Kong. Res. J. 1(1) : 38-41, 2014

Kongunadu Arts and Science College, Coimbatore

\title{
SCREENING OF PHYTOCHEMICAL CONSTITUENTS IN SOLVENT EXTRACTS OF ACORUS CALAMUS
}

\author{
Gunavathy, N.* and N. Megala \\ Department of Chemistry, Nirmala College for Women, Coimbatore, Tamil Nadu, India. \\ *Email: gunavathykrishnaprakash@yahoo.co.in
}

\section{ABSTRACT}

Plants have the ability to synthesize mixtures of structurally diverse bio-active compound, with multiple and mutually potential therapeutic effects. Acorus calamus a medicinal harp is known to be rich in $\beta$ asarone in its composition. The rhizome of this plant appears to have traditional usage for the treatment of insomnia, melancholia, remittent fever, delirium, neurosis, cough etc. The solvent extracts of the drug yielding plants were subjected for preliminary phyto-chemical screening, before evaluation of their biological activity. The curative properties of medicinal plants are perhaps due to the presence of various secondary metabolites such as alkaloids, flavonoids, glycosides, phenols, saponins, sterols etc. The successive extracts of root of Acorus calamus revealed the presence of tannins, flavonoids, steroids, glycosides, alkaloids, proteins and phenols. The preliminary screening tests may be useful in the detection of the bioactive principles and subsequently may lead to the drug discovery and development.

Keywords: Acorus calamus, Phytochemical constituents.

\section{INTRODUCTION}

Phyto-chemicals are the individual chemicals; the plant comprises of, and has the capacity of manufacturing the secondary products. The phyto-chemicals with antioxidant properties, tend to be brightly colored because they contain chromospheres, a series of alternating singlebonded carbons. Isoprene is often the building block of such units, and abundantly found in the chlorophyll and the required antioxidants. Hundreds of phyto-chemicals are currently being studied and are believed to have major positive impact on human health. Important plant secondary metabolites have been isolated over a period of time from natural sources. The phyto-chemicals belong to the following categories such as terpenoids, phenolic compounds, alkaloids, glycosides, carbohydrates, lipids, proteins, nucleic acids, etc. (Raaman, 2006).

Binomially named Acorus calamus (Sweet flag) (Figure 1) is a seasoning and medicinal herb used in both Indian medicine (Ayurveda) and traditional Chinese medicine for its cognitive properties. Acorus calamus is a tall perennial wet land monocot of the Acoraceae family of the genus Acorus calamus. The scanted rhizomes (Figure 2) have traditionally been used medicinally and to make fragrances and the dried powdered rhizome (Figure 3) has been used as a substitute for ginger, cinnamon and nutmeg (Raja et al., 2009).

Sweet flag has a very long history of medicinal use in Chinese and Indian herbal traditions. The leaves, stems, and roots are used in various Siddha and Ayurvedic medicines (Avadhini and Mythili, 2013). It is widely employed in modern herbal medicine, as it has sedative, laxative, diuretic and carminative properties (Balakumbahan et al., 2010; Simonetti, 1990). It is used in Ayurveda to counter the side effects of all hallucinogens. Sweet flag, known as "Rat Root" is one of the most widely and frequently used herbal medicines amongst the Chipewyan people (Johnson et al., 1995).

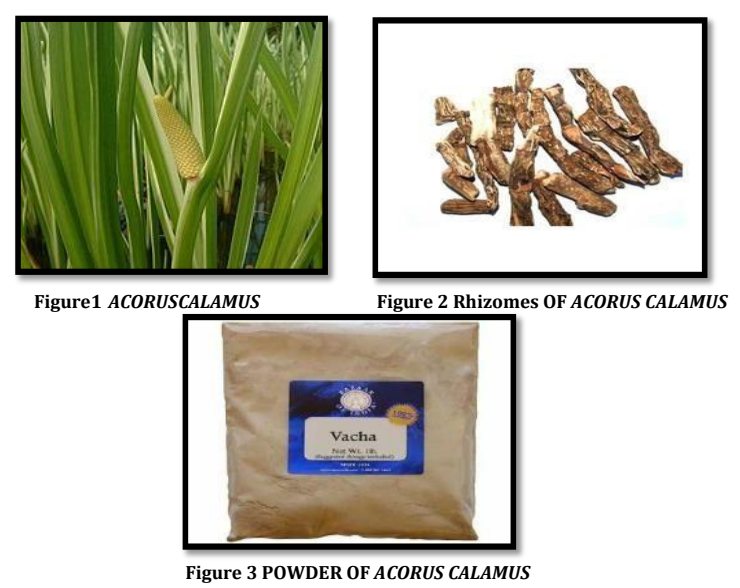

Both triploid and tetraploid Acorus calamus contains alpha-Asarone (Simonetti, 1990) and the other Phyto-chemical includes.

Phyto-chemical screening for the presence of tannin, phlobatannin, saponin, flavonoids, steroids, glycosides, alkaloids, carbohydrates, proteins and phenols, in different solvent systems 
was carried out to standardize, the suitable solvent for extraction and the detection of the compounds that is eluted with the solvent. Further, these tests facilitate their quantitative estimation and qualitative separation of pharmacologically active chemical compounds.

\section{MATERIALS AND METHODS}

\subsection{Preparation of extracts}

For aqueous extraction, $10 \mathrm{~g}$ of air-dried powder was added to distilled water and boiled on slow heat for $2 \mathrm{~h}$. It was then filtered through 8 layers of muslin cloth and centrifuged for 10 minutes. The supernatant was collected, this procedure was repeated twice. After $6 \mathrm{~h}$, the supernatant collected at an interval of every $2 \mathrm{~h}$, was pooled together and concentrated to make the final volume one-fourth of the original volume (Parekh et al., 2005). It was then autoclaved at $121^{\circ} \mathrm{C}$ temperature and at $15 \mathrm{lbs}$ pressure and stored at $4^{\circ} \mathrm{C}$. For solvent extraction, $10 \mathrm{~g}$ of air-dried powder was taken in $100 \mathrm{ml}$ of organic solvent (methanol or ethanol) in a conical flask, plugged with cotton wool and then kept on a rotary shaker at $190-220 \mathrm{rpm}$ for $24 \mathrm{~h}$. After $24 \mathrm{~h}$ the supernatant was collected and the solvent was evaporated to make the final volume one-fourth of the original volume (Parekh et al., 2005) and stored at $4^{\circ} \mathrm{C}$ in airtight bottles.

\subsection{Phyto-chemical screening}

Chemical tests were carried out on the aqueous extracts of Acorus calamus and on the powdered specimens using standard procedures to identify the constituents eluted in the solvent extracts (Harborne et al.,1998).

\subsubsection{Test for tannins}

About $0.5 \mathrm{~g}$ of the dried powdered sample was boiled in $20 \mathrm{ml}$ of water in a test tube and then filtered. A few drops of $0.1 \%$ ferric chloride was added and observed for brownish green (or) a blue black coloration.

\subsubsection{Test for phlobatannins}

Deposition of a red precipitate when an aqueous extracts of each plant sample was boiled with aqueous hydrochloric acid was taken as evidence for the presence of phlobatannins.

\subsubsection{Test for saponins}

About $0.5 \mathrm{~g}$ of the powered sample was boiled in $20 \mathrm{ml}$ of distilled water in a water bath and filtered. $10 \mathrm{ml}$ of the filtrate was mixed with $5 \mathrm{ml}$ of distilled water and shaken vigorously for a stable persistent froth. The frothing was mixed with 3 drops of olive oil and shaken vigorously, then observed for the formation of emulsion.

\subsubsection{Test for flavonoids}

Following methods were used to determine the presence of flavonoids in the plant sample. $0.5 \mathrm{ml}$ of dilute ammonia solution was added to a portion of the aqueous filtrate of each plant extract followed by addition of $\mathrm{H}_{2} \mathrm{SO}_{4}$ (Harborne et al., 1998). A yellow coloration disappeared on standing. Few drops of $1 \%$ aluminum solution were added to a portion of each filtrate. A yellow coloration was observed indicating the presence of flavonoids. A portion of the powered plant sample was in each case heated with $10 \mathrm{ml}$ of ethyl acetate over a steam bath for 3 minutes. The mixture was filtered and $4 \mathrm{ml}$ of the filtrate was shaken with $1 \mathrm{ml}$ of dilute ammonia solution. A yellow colouration observed indicate a positive test for flavonoids.

\subsubsection{Ferric chloride test}

To a small quantity of the alcoholic solution of the extracts a few drops of neutral ferric chloride solution was added. A green colour produced indicates the phenol nucleus.

\subsubsection{Zinc-hydrochloride acid reduction test}

To the alcoholic solution of the extracts a pinch of zinc dust was added and few drops of concentrated hydrochloric acid were added. Magenta color would be produced after a few minutes. Flavanones and dihydro flavanols at the presence of $\mathrm{HCl}$ produce bright red color, isoflavonoids and flavones develop yellow, sometimes red colour, and flavonoles do intensive red colour.

\subsubsection{Test for steroids}

$2 \mathrm{ml}$ of acetic anhydride was added to $0.5 \mathrm{~g}$ ethanolic extracts of each sample with $2 \mathrm{ml} \mathrm{H}_{2} \mathrm{SO}_{4}$. The color change from violet to blue or green in same samples indicates the presence of steroids.

\subsubsection{Salkowski reaction}

To the $0.5 \mathrm{ml}$ of chloroform extract in a test tube $0.1 \mathrm{ml}$ of concentrated sulphuric acid was added from the sides of the test tube. A reddish brown colour observed in chloroform layer indicate the presence of steroids

\subsubsection{Libermann Buchardt test}

To $1 \mathrm{ml}$ of petroleum ether extracts in chloroform, $1 \mathrm{ml}$ of concentrated sulphuric acid was added followed by the addition of $2 \mathrm{ml}$ of acetic an hydride solution and mixed well. A greenish colour developed and turned indicate the presence of steroids. 


\subsubsection{Test for cardiac glycosides (Keller-Killani test)}

$5 \mathrm{ml}$ of each extracts was treated with $2 \mathrm{ml}$ of glacial acetic containing one drop of ferric chloride solution. This was treated with $1 \mathrm{ml}$ of concentrated sulphuric acid. A brown ring of the interface indicates a deoxy sugar characteristic of cardenolides. A violet ring may appear below the brown ring, while in the acetic acid layer, a greenish ring may form just gradually throughout thin layer (Harborne, 1973).

\subsubsection{Test for alkaloids}

\subsubsection{Mayer's test}

The various extracts were distilled in chloroform. The chloroform was acidified and added few drops of Mayer's reagent (potassium mercuric iodide). Formation of a creamy white precipitate indicates the presence of alkaloids.

\subsubsection{Dragendroff's test}

The various extracts were dissolved in chloroform. The chloroform was evaporated and the residue was acidified and added few drops of Dragendroff's reagent (potassium bismuth iodide) appearance for orange red precipitate was observed.

\subsubsection{Test for carbohydrates}

\subsubsection{Fehling's test}

The extracts with heated with Fehling's A and B solution formation of an orange red precipitate show the presence of reducing sugar.

\subsubsection{Molisch's test}

The extracts with Molisch's reagent and added concentrated sulphuric acid along the sides to form layers. A reddish violet ring at the interference show the presence of carbohydrate. Monosaccharide's give a rapid positive test. Disaccharides and polysaccharides react slower.

\subsubsection{Test for proteins}

\subsubsection{Biuret test}

The Biuret test is often used to determine the presence of peptide bonds in protein. When a protein reacts with copper (II) sulfate (blue), the positive test is the formation of a violet coloured complex.

\subsubsection{Ninhydrin test}

The Ninhydrin test is a test for amino acids and proteins with a free $-\mathrm{NH}_{2}$ group. When such an $\mathrm{NH}_{2}$ group reacts with ninhydrin, a purple-blue complex is formed.

\subsubsection{Test for Phenols}

\subsubsection{Reaction with $\mathrm{FeCl}_{3}$}

Phenol gives violet colouration with neutral ferric chloride solution due to the formation of a coloured iron complex, which is a characteristic to the existence of keto-enol tautomerism in phenols (predominantly enolic form).

\section{RESULTS}

In the present investigation, various solvent extracts of Acorus calamus was analyzed for the elution of the significant primary and secondary metabolites to assess the suitability of the solvents and to know the interfering substances present in the particular solvents extract. The results are summarized in (Table 1).

The aqueous and methanolic extracts were tested for flavonoids, tannin, protein, glycosides, phenol, steroids, alkaloids and their presence was confirmed. The tests for carbohydrate, saponin showed the absence of the compounds. (+) is presence of compounds, (-) is absence of compounds in phyto-chemical analysis.

\section{DISCUSSION}

The investigated plants did not show strong antibacterial activity; however, negative results do not mean absence of bioactive constituents nor is that the plant inactive. Active compound(s) may be present in insufficient quantities in the crude extracts to show activity with the dose levels employed (Taylor et al., 2001). Lack of activity can thus only be proven by using large doses (Farnsworth, 1993). Alternatively, if the active principle is present in high enough quantities, there could be other constituents exerting antagonistic effects or negating the positive effects of the bioactive agents (Jager et al., 1996).

Preliminary phyto-chemical analysis of Acorus calamus revealed the presence of alkaloids and flavonoids, though the latter was in lesser amount. The other secondary metabolites like tannins, phenols, steroids, cardiac glycosides, etc were present in trace amounts in some of the extracts, which could contribute to the differences in the activities of extracts, due to phyto-chemical properties and differences among species.

The tests for carbohydrate, and saponin showed the absence of the compounds. Kaushik et al., (2012) reported the presence of carbohydrate, tannin, terpenoids, glycoside, saponin, flavonoid, and the absence of amino acid, alkaloid and steroid. Ashok et al., (2012) reported the presence of 
carbohydrate, flavonoid, steroids, glycosides, alkaloids, tannin, and the absence of saponin. Savitha et al., (2010) reported the presence of alkaloid, carbohydrate, protein, glycosides, phenol, tannin, and the absence of amino acid, steroid, saponin and terpenoids, where as in the present studies the extracts showed the presence of alkaloid, flavonoid, tannin, protein, glycosides, phenols, steroids, and the absence of carbohydrate and saponin.

\section{ACKNOWLEDGEMENT}

The authors express deep sense of gratitude to Dr. K. Latha, Herbal Division, T. Stanes and Company Limited, Coimbatore, for her technical guidance and encouragement for success of this research.

\section{REFERENCES}

Ashok, A.K., D. Bhat Savitha and Acharya Rabinarayan. (2012). Exploring the concept of Vacha (Acorus calamus Linn) Shodhana in Ayurveda. Int. J. Ayur. Res. Pharma 3(3): 341344.

Balakumbahan, R., K. Rajamani and K. Kumanan. (2010). Acorus calamus an overview. J. Medicinal plant Res 4(25): 2740-2745.

Farnsworth, N.R. (1993). Biological approaches to the screening and evaluation of natural products. In: Rasoanaivo $\mathrm{P}$, Ratsimamanga Urverg S (Eds). Biological evaluation of plants with reference to the Malagasy Flora, Madagascar. 35-48.

Harborne, J.B. and A. Harborne. (1998). Phytochemical method-A guide to modern techniques of plant analysis. $3^{\text {rd }}$ Edition, Chapman and Hill, London. 114-118.

Harborne, J.B. (1973). Phytochemical methods. Chapman and Hill Ltd, London.

Jager, A.K., A. Hutchings, A.K. van Stadenj. (1996). Screening of Zulu medicinal plants for prostagland in synthesis inhibitors. J. Ethnopharmacol 52: 95-100.

Johnson, D., Linda Kershaw, Andy Mackinnan, Jim Pojar and Trevor Goward. (1995). Plants of the
Western Boreal forest and Aspen Parkland, Lone Pine Publishing, USA.

Kaushik, R., Sharma Binu, Gupta Deepika, Jain Jainender and Patel Push Pendra. (2012). Establishment of monograph of Acorus calamus Linn. Rhizomes. J. Drug Delivery and Therapeutics. 2(3): 136-140.

Mythili Avadhani, M.N., C. Immanuel Selvaraj, P.E. Rajasekharan and C. Tharachand. (2013). The sweetness and bitterness of sweet flag (Acorus calamus L) - A review. Res. J. Pharmaceut. Biol. Chem. Sci 4(2): 598-610.

Parekh, J., R. Nair and S. Chand. (2005). Preliminary screening of some folklore medicinal plants from Western India for potential antimicrobial activity. Indian J. Pharmacol. 37: 408-409.

Raaman, N. (2006). Quantitative analysis of phytochemicals. Phytochemical Techniques. New India Publishing, New Delhi.

Raja, A.E., M. Vijayalakshmi and G. Devala Rao. (2009). Acorus calamus Linn. Chemistry and biology. Res. J. Pharma. Technol 2(2): 256-261.

Simonetti, W. and S. Gualtiero. (1990). Simon and Schuster's Guide to herbs and spices. Edited by Stanley Schuler.

Taylor, 0J.L.S., T. Rabe, Mc Graw, L.J. Jager and A.K. van Stadenj. (2001). Towards the scientific validation of traditional medicinal plants. Plant Growth Regulation 34: 23-27.

Table 1. Phyto-chemical analysis of the solvent extracts

\begin{tabular}{clc}
\hline S. & \multicolumn{1}{c}{ Analysis } & Compounds confirmed \\
No & & + \\
\hline 1 & Tannins & - \\
2 & Saponins & + \\
3 & Flavonoids & + \\
4 & Steroids & + \\
5 & Glycosides & + \\
6 & Alkaloids & - \\
7 & Carbohydrates & + \\
8 & Proteins & + \\
9 & Phenols & + \\
\hline
\end{tabular}

